\section{Molecular Discrimination of Lemon Cultivars}

\author{
Guillermo P. Bernet, Pedro F. Mestre, José A. Pina, and María J. Asíns ${ }^{1}$ \\ Instituto Valenciano de Investigaciones Agrarias (IVIA), Apdo. Oficial, 46113 \\ Moncada (Valencia), Spain
}

Additional index words. IRAP, ISSR, RAPD, retrotransposons, somatic variation, Citrus limon

\begin{abstract}
Some lemon [Citrus limon (L.) Burm. f.] cultivars present compatibility problems with commonly used citrus rootstocks. Therefore, assessing trueness-to-type of lemon mother trees is needed by growers. Morphological differentiation of lemon cultivars is not precise because they present high phenotypic plasticity. The objective of this paper is to contrast the discriminatory ability of several molecular marker systems for lemon. Three marker types were used: randomly amplified polymorphic DNA (RAPD), inter-simple sequence repeats (ISSR) and inter-retrotransposon amplified polymorphism (IRAP). The molecular variability found in $C$. limon is larger than that reported for $C$. clementina, another vegetatively propagated citrus species. This difference in variability content might be explained by differences in the distribution and age of both cultures. Similar to clementines, polymerase chain reaction (PCR) markers using primers anchored in copya-like retrotransposons resulted in a higher rate of polymorphisms $(36.4 \%)$ than did primers of random sequence $(27.3 \%)$ or those anchored at simple sequence repeats $(0 \%)$, indicating a higher molecular variability at the locations where these retrotransposons inserted. Primers anchored in gypsy-like retroelements did not yield polymorphisms. Lemon cultivars from important groups such as 'Eureka', 'Fino', and 'Verna' could be distinguished using all polymorphisms.
\end{abstract}

The production of the most important fruit tree, citrus, was estimated world-wide at more than 103 million MT in 2000. Within citrus, as a group of crop species, lemon and lime $(C$. latifolia Tan.) are the third in yield (9.8 million MT) following sweet orange $[C$. sinensis $(\mathrm{L}$.) Osbeck] and mandarins (C. clementina Hort. ex Tan., C. unshiu Marc., and artificial hybrids) (FAO, 2000).

Given the high heterozygosity of C. limon (Herreroet al., 1996a) and its close relationship to $C$. medica L. (citron), a hybrid origin from the latter species has been suggested by several authors (Barret and Rhodes, 1976; Herrero et al., 1996b; Malik et al., 1974). Lemon was considered by Linnaeus to be a variety of citron. Lemon was actively spread in the Mediterranean region by the Arabs about 1000 to 1200 A.D. Like sour orange, it became widely and favorably known as a medicinal agent (Swingle, 1943).

As with other important cultivated citrus, $C$. limon shows low genetic variability (Herrero et al., 1996a). This is explained by the origin of most of its cultivars by somatic mutation and nucellar variation (Frost and Soost, 1968). Lemon cultivars are generally classified into four major types: the Italian 'Femminello', the Spanish 'Verna' and 'Fino', and the 'Eureka'

Received for publication 18 Oct. 2002. Accepted for publication 4 Feb. 2003. We are grateful to Dr. Emilio A. Carbonell for statistical analysis and helpful comments, and Dr. Luis Navarro for allowing us the use of the Citrus Germplasm Bank at IVIA. This work was supported by research grants INIA (SC99-047) and Conselleria de Cultura, Educació i Ciència (GPB).

${ }^{1}$ To whom reprint requests should be addressed. E-mail:mjasins@ivia.es type originated in Los Angeles, Calif., from an Italian fruit (Hodgson, 1967). Their morphologic classification is very difficult because horticultural traits of both tree and fruit are extremely variable and markedly affected by environmental influences (Hodgson, 1967). This differentiation is important because some lemon cultivars present incompatibility problems with certain rootstocks. For instance, if a 'Verna' lemon is grafted on sour orange, affinity problems between both appear at the union (scion overgrown) that limit the time of tree profitability (25 years at most); More dramatically, if a 'Eureka' lemon is grafted on 'Carrizo' or 'Troyer' citrange, it will develop incompatibility disorders in few years. Therefore, the trueness-to type of mother trees has to be ensured to avoid such problems (Barry et al., 1999). Several molecular markers have been used to differentiate between lemon genotypes, and opposing results have been found comparing isozymes and restriction fragment length polymorphisms (RFLPs) vs. RAPDs and ISSRs. Isozyme systems (Gulsen and Roose, 2001; Herrero et al., 1996a; Protopapadakis and Papanikolau, 1999; Torres et al., 1978) and RFLPs (Albanese et al., 1992) have revealed low intraspecific variability. On the other hand, Deng et al. (1995) could distinguish 16 lemon genotypes using 43 RAPDs based on 36 primers. Similarly, Fang and Roose (1997) could differentiate five of six lemon cultivars using ISSRs.

Bretó et al. (2001) observed that the amplification of sequences adjacent to retrotransposons in C. clementina (another the highest number of polymorphisms when compared to RAPD, ISSR, AFLP, and SSR vegetatively propagated citrus species) yielded markers. Inter-retrotransposon amplified polymorphism(IRAP; Kalendaretal., 1999) is a very simple and repeatable molecular marker that is based on retrotransposon sequences that have been found to be abundant through the genome of citrus (Asíns et al., 1999). The objective of this study is the molecular characterization of a representative collection of lemon cultivars to facilitate an early classification of lemon genotypes. For this purpose, several types of molecular markers, including IRAPs based on copya and gypsy retrotransposons from citrus, were used.

\section{Materials and Methods}

Thirteen lemon accessions (Table 1) covering a wide range of morphological variation were chosen from the citrus germplasm bank at Instituto Valenciano de Investigaciones Agrarias (IVIA). Three types of DNA markers - RAPD, IRAP, and ISSR - were used to study their variability at the molecular level.

At least two DNA extractions from $1 \mathrm{~g}$ of leaf tissue percultivar were obtained following the methods of Dellaporta et al. (1983) with minor modifications. To assess repeatability, $\mathrm{PCR}$ reactions were performed in duplicate and from different DNA extractions.

$R A P D s$. A total of 22 primers ( 10 mers from Operon Technologies Inc., Alameda, Calif.) were used for PCR reactions. Primers A4, A7, A11,A13,E8, E14, and W15 were used because Deng et al. (1995) had reported RAPDs that could distinguish some 'Feminello', 'Fino', 'Eureka', and 'Verna' lemon cultivars. Primers B7, D18, D20, F2, F7, G7, and G11 were also used to contrast our results with Russo et al. (1998). Primers I4 and K19 were used because they yielded polymorphisms among 'Eureka' and 'Lisbon' lemon cultivars (Barry et al., 1999). Primers E15 and I6 were used because they provided polymorphisms in $C$. clementina (Bretó et al., 2001), and primers A14 and B20 because they provided polymorphisms in C. sinensis (Herrero, 1995). The remaining two primers (E19, O4) were randomly chosen.

The $25-\mu \mathrm{L}$ amplification reactions consisted of $150 \mathrm{ng}$ of template DNA, $1 \times$ supplied reaction buffer, $1.5 \mathrm{mM} \mathrm{MgCl}_{2}, 100$ $\mu \mathrm{M}$ each dNTP, $0.2 \mu \mathrm{M}$ primer, and $1 \mu$ Taq (EcoTaq, Ecogen, Barcelona, Spain). Each reaction was overlaid with $25 \mu \mathrm{L}$ of mineral oil, and amplified in a MJ Research (Waltham, Mass.) thermal cycler. The cycling profile was: $95^{\circ} \mathrm{C}, 5 \mathrm{~min} ; 45$ cycles of $95^{\circ} \mathrm{C}(1 \mathrm{~min}), 44$ ${ }^{\circ} \mathrm{C}(1 \mathrm{~min})$, a slope of $+0.3^{\circ} \mathrm{C}$ per s, and 72 ${ }^{\circ} \mathrm{C}(2 \mathrm{~min})$, and a final extension at $72{ }^{\circ} \mathrm{C}(8$ min). For primers A13, E8, and W15, another thermocycling program was assayed according to Deng et al. (1995), but no difference was observed between both programs. PCR products were mixed with $5 \times$ loading buffer $(50 \% \mathrm{v} / \mathrm{v}$ glycerol, $1 \times$ TAE, $10 \%$ v/v saturated bromophenol blue, $0.2 \% \mathrm{w} / \mathrm{v}$ xylene cyanole), and visualised by polyacrylamide-silver staining: sequencing-type $10 \%$ polyacrylamide gels, in $1 \times \mathrm{TBE}$ and fixed to the glass. Electrophoresis conditions were $20 \mathrm{~W}, 30 \mathrm{~min}$, and $40 \mathrm{~W}$ until the bromophenol-blue dye reached the bot- 
Breeding, Cultivars, Rootstocks, \& Germplasm Resources

tom of the gel, in an S2 Sequencing System (Gibco BRL/Life Technologies, Gaitherburg, Md.). Silver staining was performed according to Ruiz et al. (2000).

ISSRs. Eleven of the primers for inter-simple sequence repeat analysis used by Fang and Roose (1997) to differentiate citrus varieties were screened. All of them were primers anchored at the $3^{\prime}$ end, and part of UBC primer Kit \#9 from the Biotechnology Laboratory, Univ. of British Columbia, Canada. The amplification mix was similar to the one described for RAPDs, but $25 \mathrm{ng}$ of DNA were used as template, and it contained $2 \%$ formamide and 1 $\mu \mathrm{M}$ primer. Two different $\mathrm{PCR}$ programs were used: for $(A G)$ and $(G A)$ repeats it consisted of $94{ }^{\circ} \mathrm{C}, 7 \mathrm{~min} ; 2$ cycles of $94^{\circ} \mathrm{C}(1 \mathrm{~min})$, $35^{\circ} \mathrm{C}(1 \mathrm{~min})$, a slope of $+0.3^{\circ} \mathrm{C}$ per s, and $72{ }^{\circ} \mathrm{C}(2 \mathrm{~min}) ; 35$ cycles of $94{ }^{\circ} \mathrm{C}(1 \mathrm{~min}), 45$ ${ }^{\circ} \mathrm{C}(1 \mathrm{~min})$, a slope of $+0.3{ }^{\circ} \mathrm{C}$ per sec, and 72 ${ }^{\circ} \mathrm{C}(2 \mathrm{~min})$, and a final extension at $72{ }^{\circ} \mathrm{C}(7$ min). For (CA), (AC) and (GT) repeats the cycling profile was $94{ }^{\circ} \mathrm{C}, 7 \mathrm{~min} ; 40$ cycles of $94{ }^{\circ} \mathrm{C}(1 \mathrm{~min}), 52{ }^{\circ} \mathrm{C}(1 \mathrm{~min})$, a slope of $+0.3^{\circ} \mathrm{C}$ per sec, and $72^{\circ} \mathrm{C}(1 \mathrm{~min})$, and a final extension at $72^{\circ} \mathrm{C}(7 \mathrm{~min}) . \mathrm{PCR}$ products were electrophoresed and revealed as described for RAPDs (polyacrylamide gels).

IRAPs. Eight primers were designed from four citrus sequences that had homology with the RT domain of the copya family. The sequences were CL3, CL5, and CL6 from clementines, and SI4 from Citrus sinensis (Bretó et al., 2001). The primers were denoted $\mathrm{R}$ or $\mathrm{F}$ (reverse or forward) for each sequence. Four combinations of primers designed from four citrus sequences having homology with the RT and Integrase domains of the gypsy family were also used. Primers were used in pairs, to amplify intertransposonic sequences. PCR conditions, electrophoresis and visualisation were similar to those described for RAPDs, but $300 \mathrm{ng}$ of DNA and $0.12 \mu \mathrm{M}$ of each primer were used instead for amplification reactions.

A dendrogram based on the relative frequency of presence/absence of polymorphic bands was obtained using the Prevosti distance (Wright, 1978) and the unweighted pair-group method with arithmetic average for aggregation (UPGMA) (Sneath and Sokal, 1973). A phylogenetic diagram based on the accumulation of mutations and loss of IRAP bands was also represented (Bretó et al., 2001).

\section{Results and Discussion}

Six out of 22 RAPD primers resulted in polymorphisms $(27.3 \%)$ while 11 primer combinations based on four copya-RT clones resulted in differentiations $(36.4 \%)$. No polymorphism was found using ISSRs nor IRAP markers derived from gypsy-like retrotransposons (Fig. 1).

The molecular characterization of lemon accessions is presented (Table 1). Except for polymorphisms obtained with primers K19, B20, and 6F5R, most polymorphic markers distinguish one accession from the others. The Spanish 'Verna' and 'Fino' lemon cultivars are clearly distinguished by one IRAP(6F5R-325) and RAPDs with primer B20 (Fig. 1). 'Eureka'

Table 1. Classification of lemon genotypes by molecular markers. The number of the lemon genotypes corresponds to the Citrus Germplasm Bank accession number at IVIA. Primers F and R correspond to IRAPs. Numbers below primers correspond to the size (base pairs) of polymorphic band.

\begin{tabular}{|c|c|c|c|c|c|c|c|c|c|c|c|}
\hline & A7 & A13 & B7 & B20 & K19 & W15 & $3 F 3 R$ & $6 \mathrm{~F} 6 \mathrm{R}$ & $6 \mathrm{~F} 5 \mathrm{R}$ & $6 \mathrm{~F} 6 \mathrm{R}$ & \\
\hline $\begin{array}{l}\text { Lemon } \\
\text { accessions }\end{array}$ & 400 & 325 & 975 & $\begin{array}{c}12000 \\
1300 \\
1100\end{array}$ & 530 & 425 & $\begin{array}{r}1675 \\
1775 \\
475\end{array}$ & $\begin{array}{l}750 \\
775\end{array}$ & 325 & 2700 & \\
\hline Betera-162 & 0 & 0 & 1 & 0 & 1 & 0 & 0 & 0 & 1 & 1 & 4 \\
\hline Chaparro-370 & 0 & 0 & 1 & 0 & 1 & 0 & 0 & 0 & 1 & 1 & 4 \\
\hline Eureka Allen-88 & 0 & 0 & 1 & 0 & 0 & 0 & 0 & 0 & 1 & 1 & 3 \\
\hline $\begin{array}{l}\text { Fino-46 } \\
\text { 74-L-03 }\end{array}$ & 0 & 0 & 1 & 0 & 1 & 0 & 0 & 0 & 1 & 1 & 4 \\
\hline $\begin{array}{l}\text { Fino-49 } \\
\text { 74-L-08 }\end{array}$ & 0 & 0 & 1 & 0 & 1 & 0 & 0 & 0 & 1 & 1 & 4 \\
\hline $\begin{array}{l}\text { Fino-95 } \\
\text { Largo Abejera }\end{array}$ & 0 & 1 & 1 & 0 & 1 & 0 & 0 & 0 & 1 & 1 & 5 \\
\hline $\begin{array}{r}\text { Verna-50 } \\
74-L-02\end{array}$ & 0 & 0 & 1 & 1 & 1 & 0 & 0 & 0 & 0 & 1 & 4 \\
\hline $\begin{array}{r}\text { Verna-62 } \\
74-L-09\end{array}$ & 0 & 0 & 1 & 1 & 1 & 0 & 0 & 0 & 0 & 1 & 4 \\
\hline $\begin{array}{l}\text { Verna-96 } \\
\text { Febre }\end{array}$ & 0 & 0 & 1 & 1 & 1 & 0 & 0 & 0 & 0 & 1 & 4 \\
\hline $\begin{array}{l}\text { Verna-251 } \\
\text { Librilla }\end{array}$ & 0 & 0 & 1 & 0 & 0 & 0 & 0 & 0 & 1 & 1 & 3 \\
\hline $\begin{array}{l}\text { Feminello-398 } \\
\text { Apireno Greco }\end{array}$ & 0 & 0 & 1 & 0 & 1 & 0 & 0 & 0 & 1 & 1 & 4 \\
\hline $\begin{array}{l}\text { Feminello-445 } \\
\text { Zagara Bianca }\end{array}$ & 0 & 0 & 0 & 0 & 1 & 0 & 0 & 0 & 1 & 0 & 2 \\
\hline Dulce-443 & 1 & 0 & 1 & 0 & 1 & 1 & 1 & 1 & 1 & 1 & 8 \\
\hline$\overline{\text { Total }}$ & 1 & 1 & 12 & 3 & 11 & 1 & 1 & 1 & 10 & 12 & \\
\hline
\end{tabular}

lemon is distinguished from the other lemons by RAPD K19-530 (Fig. 1).

The classification of 'Librilla' ('Verna' 251) by molecular markers in the same group as 'Eureka' lemons suggests that this lemon cultivar could have been misclassified in origin and should be compared morphologicaly with the 'Eureka' accessions. Therefore, further morphologic and citrange-compatibility studies of this cultivar are needed.

Some of the ISSR primers used in this study were reported by Fang and Roose (1997) to distinguish among 'Lisbon' and 'Eureka' cultivars. None of them were polymorphic in our survey. ISSR markers have been used for identification of closely related citrus cultivars, including some lemon genotypes (Fang and Roose, 1997) and also to study the diversity and relationships among lemons and related species (Gulsen and Roose, 2001). While most lemon genotypes are identified in the first paper, low molecular variability is found among lemon cultivars in the second. These opposing results may be explained by the reduced (and probably biased) sample of lemon cultivars under the first study. In addition to the set of sampled genotypes, the discriminating ability of any marker system is relative and comparisons among marker systems have to be carried out using the same sample of genotypes. We did such comparison in $C$. clementina (Bretó et al., 2001) and present results in C. lemon confirm the greater discriminating ability of IRAPs vs. ISSRs for these vegetatively propagated species.

A few polymorphic RAPDs were found among lemon cultivars. The molecular variability found for RAPDs is upward biased because most primers were chosen due to their good results in previous studies in C. limon, C. clementina, and C. sinensis. One of the four primers used to distinguish cultivars within the last two Citrus species resulted in differentiation of lemon cultivars. Amplification products obtained using primers following Deng et al. (1995) failed to reproduce the polymorphisms that they had reported previously among 'Eureka', 'Fino,' and 'Verna' (one cultivar of each group). The lack of reproducibility among laboratories for RAPD markers has been already reported (Jones et al., 1997). Three main factors are responsible for reproducibility problems of RAPDs given a certain plant species: the association Taq polymerase-buffer- $\mathrm{MgCl}$, the DNA preparation, and the primer. We have also found that the method used in resolution of amplification products is very important to assess these factors. Each band should correspond to a single amplification product but the resolution power of agarose gels is very low compared to acrylamide gels (Huff and Bara 1993; Smith et al., 1997). Additionally, for routine utilization of these polymorphisms, their conversion to other types of PCR marker, based on two specific primers like a SCAR (sequence characterized amplified region), is highly recommended.

The molecular variability found for IRAPs in the present survey of lemon genotypes is larger than that reported for $C$. clementina cultivars (Bretó et al., 2001). It might be explained by differences in the distribution and age of both cultures. Lemons are more widely distributed (Mexico, Argentina, India, Iran, Spain, mainly) and their culture is older than that of clementines, which is mostly restricted to Spain and some other Mediterranean countries.

Genetic relationships have been represented 

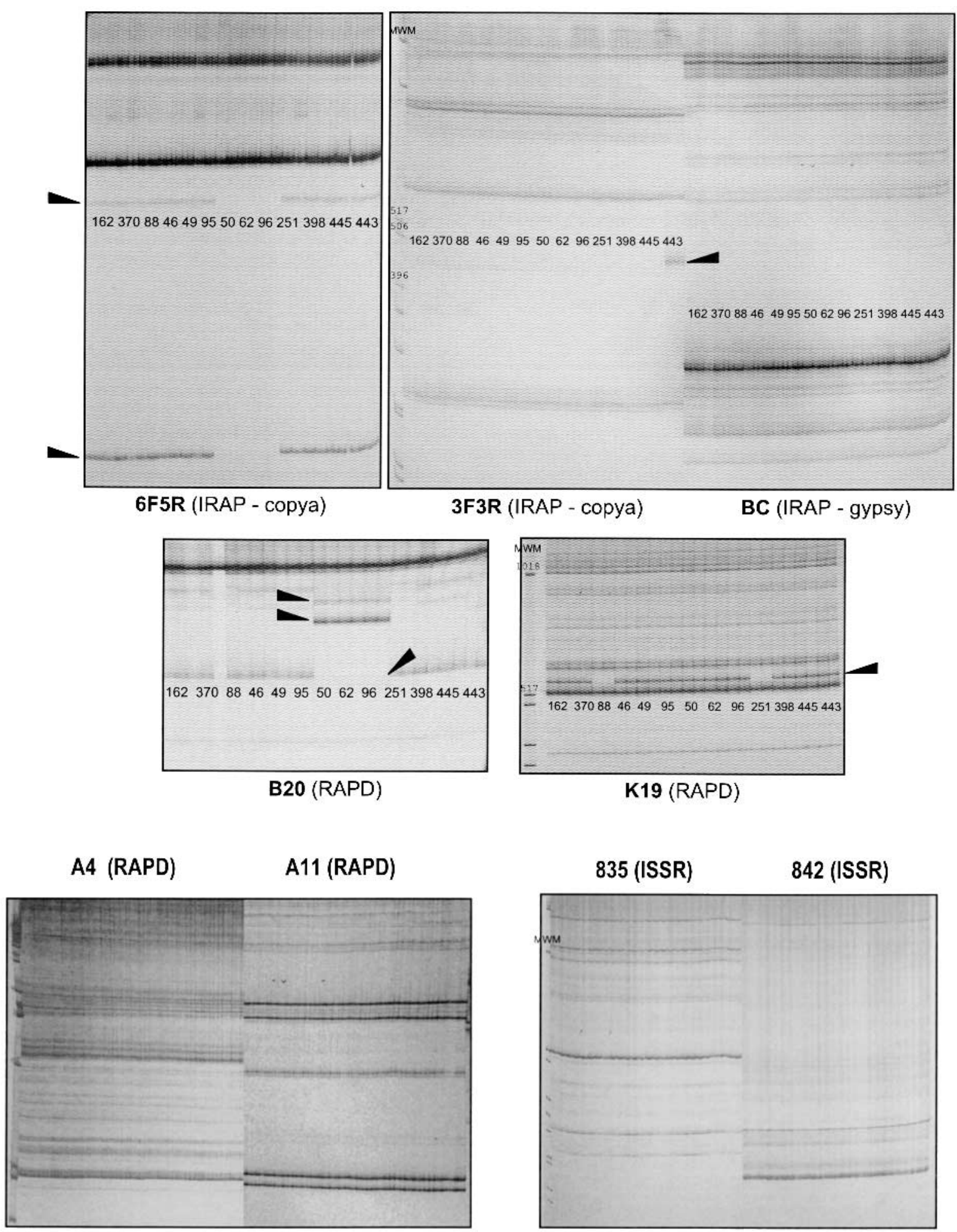

Fig. 1. Different types of molecular markers used in this survey. Lack of polymorphisms for RAPDs using primers A4 and A11, for IRAP using gypsy clone BC; and for ISSRs using primers $835\left[(\mathrm{AG})_{8} \mathrm{YC}\right]$ and $842\left[(\mathrm{GA})_{8} \mathrm{YG}\right]$. Examples of polymorphisms for RAPDs using primers K19 and B20; polymorphisms for IRAPs 3F3R and 6F5R. 


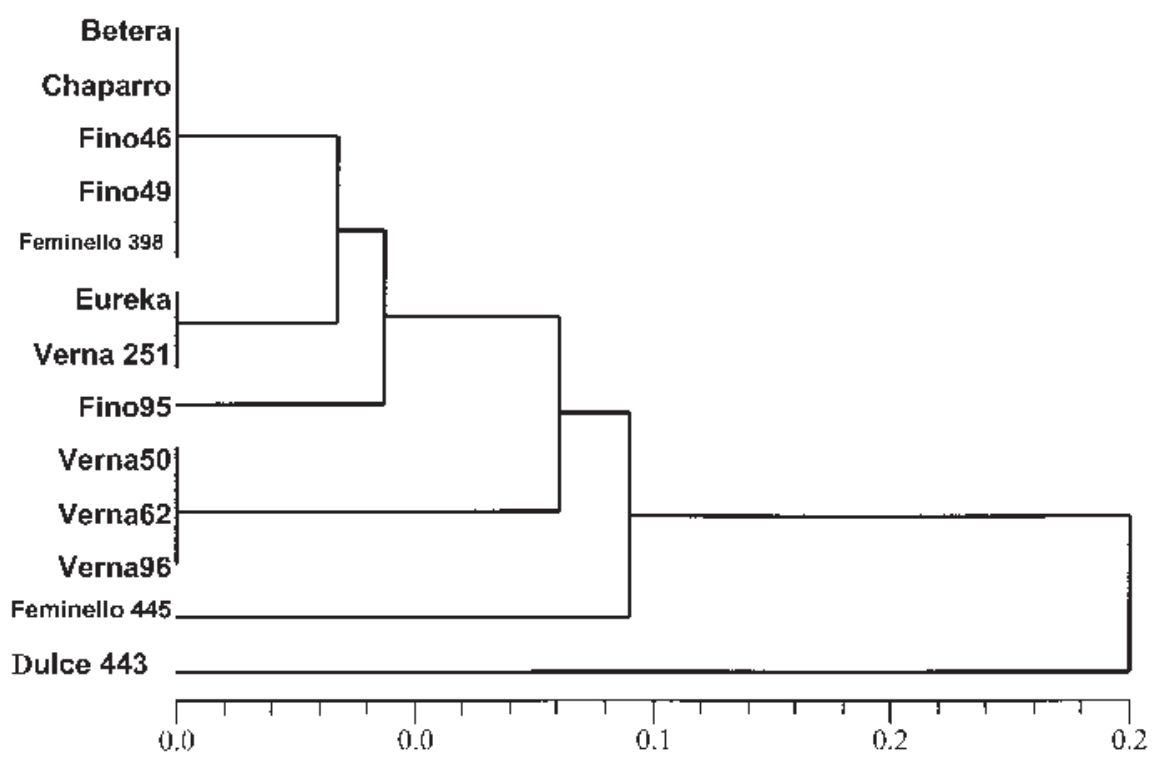

Fig. 2. Cluster analysis of lemon cultivars.

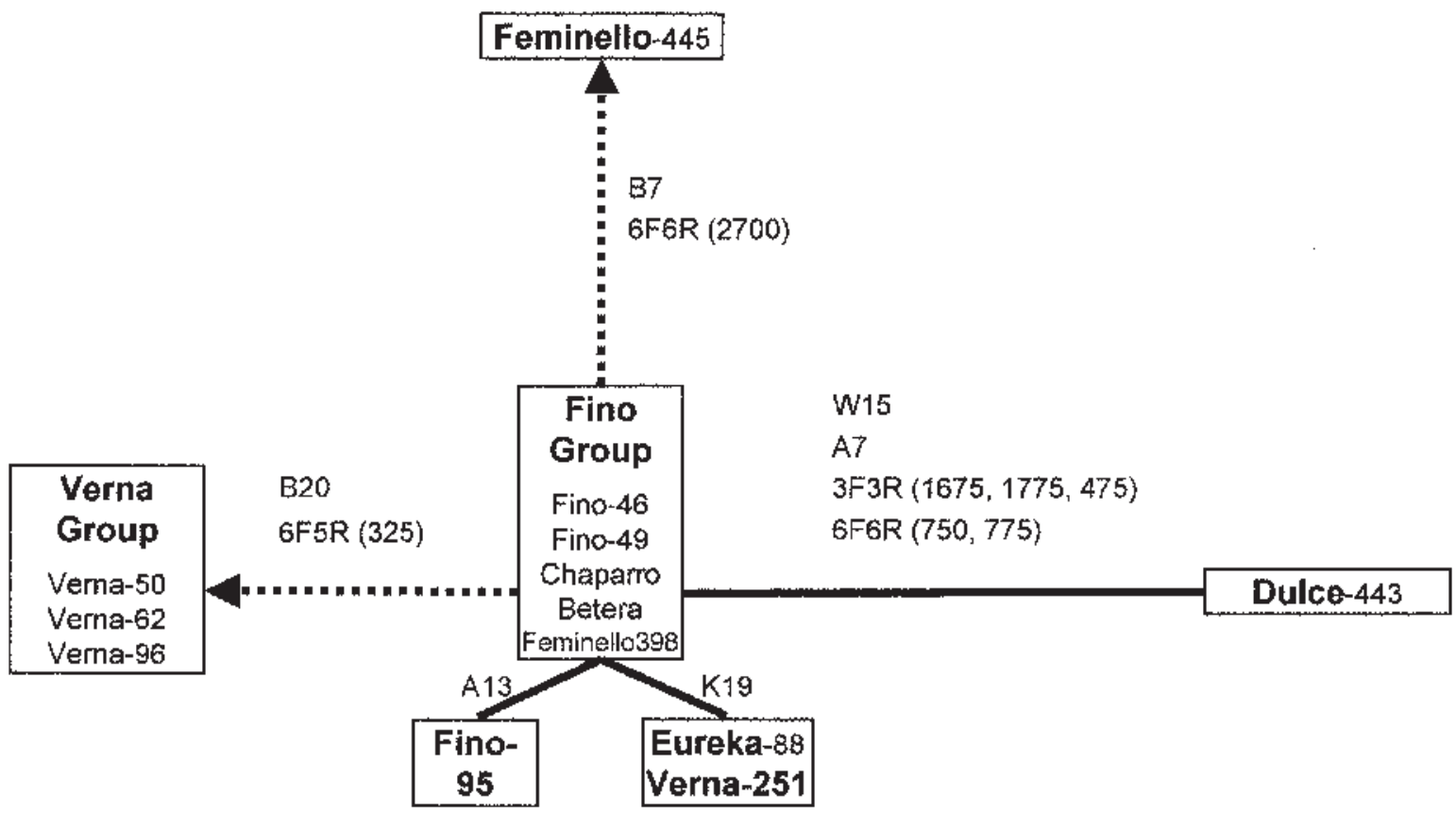

Fig. 3. Phylogenetic diagram of lemon cultivars. Discontinuous arrows mean hypothesized origin following the direction of loss of IRAP bands that are frequent in the collection.

as a dendrogram (Fig. 2) and as a diagram (Fig. 3). The most distant accession is an old one, 'Dulce', with no commercial value. Most 'Fino' accessions cluster together and so do most 'Verna' accessions. 'Eureka' lemon is more closely related to 'Fino' than to 'Verna' groups. Similar to the abovementioned study of clementines, the use of specific primers to amplify intertransposonic sequences of the copya family has been very productive in terms of cultivar discrimination and repeatability compared to RAPDs. The RT sequences involved differ: CL3, CL5, and CL6 in lemons and CL3, CL5, and SI4 in clementines. These results suggest that the process of differentiation in lemons is very similar to that of clementines, i.e., changes at copya-like retrotransposons (three out of four RT sequences) have facilitated the diversification of lemons. A diagram based on the accumulation of mutations has been drawn to show more clearly the relationships among genotypes (Fig. 3). Moreover, if, as in the case of clementines, a direction in evolution were hypothesized toward loss of frequently present IRAP bands, then the 'Fino' group, which also includes two seedless cultivars, 'Betera' and 'Feminello 398', would be the origin of 'Feminello 445' and 'Verna' groups, separately. The Italian group of cultivars, 'Feminello', seems more heterogeneous than the Spanish 'Fino' and 'Verna' groups. 'Dulce', an old sweet, or acidless, lemon accession collected in an Spanish orchard, presents RAPDs and IRAPs that no other lemon cultivar does. Federici et al. (1998) found that a lemon accession named 'Iraq' sweet lemon (CRC 3492) had been wrongly assigned to $C$. limon because, according to cluster analysis using molecular markers (RFLPs and RAPDs), it should be considered an accession of $C$. limetta Risso. This possibility has to be checked out, although $C$. limetta is not considered a separate species from $C$. limon by the most widely accepted Citrus taxonomy (Swingle, 1943). Concerning the diversification of lemon cultivars, our results differ from those reported by Gulsen and Roose (2001). The genetic relationships we have found between lemon genotypes agree with their classification into main horticultural groups ('Fino', 'Verna', and 'Eureka'). Then the most likely explanation must be the marker type. The polymorphisms we have found involve RAPD 
and IRAP markers, while most polymorphisms between lemon genotypes found by Gulsen and Roose (2001) involved ISSRs. The authors themselves found it surprising that the major horticultural groups of 'Lisbon' and "Eureka" lemon cultivars did not form discrete clusters using these polymorphisms. As they pointed out, three possible explanations might be argued: horticultural misclassification of some cultivars, polyphyletic origin of each group, and lack of usefulness of ISSR markers. Since the first and second explanations can never be ruled out, it seems advisable to avoid using ISSR markers.

The amplification of intertransposonic sequences using primers based on four gypsy retrotransposons yielded no polymorphism. Retrotransposons are subdivided into two groups on the basis of the presence/absence of long terminal direct repeats (LTRs) flanking the coding regions. LTR retrotransposons contain at least two open reading frames: GAG, (group-specific antigen) which encodes for a capsid-like protein, and POL, encoding for a polyprotein responsible of protease (pro), reverse transcriptase (rt), integrase (int), and Rnase H (rh) activities. Based on the domain structure in the POL region, LTR retrotransposons are also divided into two groups, the copya type (pro-int-rt-rh from 5' to $3^{\prime}$ end) and the gypsy type (pro-rt-rh-int). Although copya and gypsy types of retrotransposons are closely related and similar in activity (Vicient et al., 2001), IRAPs based on copya elements are more polymorphic. Linkage analysis of IRAPs has shown that gypsy elements are less abundant than copya elements in the citrus genome (Ruiz et al., 2003), which might explain the difference in polymorphism level between them.

In conclusion, very low molecular variability has been found within C. limon. This variability mostly involves genomic regions containing copya-like retrotransposons, and a set of IRAPs and RAPDs are reported here that are now available to facilitate an early classification of lemon genotypes into 'Eureka', 'Fino', or 'Verna' types.

\section{Literature Cited}

Abanese, G., M. Renis, and G. Reforgiato-Recupero. 1992. RFLPanalysis of different lemon cultivars. Proc. 6th Intl. Citrus Congr. 1:208-209.

Asíns, M.J., A.J. Monforte, P.F. Mestre, and E.A. Carbonell. 1999. Citrus and Prunus copya- like retrotransposons. Theor. Appl. Genet. 99: 503-510.

Barret, H.C. and A.M. Rhodes. 1976. A numerical study of affinity relationships in cultivated citrus and its close relatives. Systematic Bot. $1: 105-136$.

Barry, G.H., M.J. Asins, and A.L. Burger. 1999. The 'lisbon'lemon debacle. Deciduous Fruit Grower, Scientific 49:1-6.

Bretó, M.P., C. Ruiz, J.A. Pina, and M.J. Asins. 2001. The diversification of Citrus clementina Hort. ex Tan., a vegetatively propagated crop species. Mol. Phylogenetics and Evolution 21(2):85-293

Dellaporta, S.L., J. Wood, and J.B. Hicks. 1983. A plant DNA minipreparation: Version ii. Plant. Mol. Biol. Rep. 1:19-21.

Deng, Z.N., A. Gentile, E. Nicolosi, F. Domina, A. Vardi, and E. Tribulato. 1995. Identification of in vivo and in vitro lemon mutants by RAPD markers. J. Hort. Sci. 70(1):117-125.

Fang, D.Q. and M.L. Roose. 1997. Identification of closely related citrus cultivars with inter-simple sequence repeat marker. Theor. Appl. Genet. 95: 408-417.

Food and Agriculture Organization of the United Nations (FAO). Bulletin of statistics. 2000. 1(2):61.

Federici, C.T., D.Q. Fang, R.W. Scora, and M.L. Roose. 1998. Phylogenetic relationships within the genus Citrus (Rutaceae) and related genera as revealed by RFLP and RAPD analysis. Theor. Appl. Genet. 96:812-822.

Frost, H.B., and R.K. Soost. 1968. Seed reproduction development of gametes and embryos, p. 290324. In: W. Reuther, W. Webber, L.D. Burchelor (eds.). The citrus industry. Univ. of California, Berkeley.

Gulsen, O. and M.L. Roose. 2001.Lemons: Diversity and relationships with selected Citrus genotypes as measured with nuclear genome markers. J. Amer. Soc. Hort. Sci. 126:309-317.

Herrero, R. 1995. Caracterización genética y estudio de la variabilidad y de las relaciones filogenéticas en la subfamilia Aurantioideae. Tesis Doctoral. Universidad de Valencia, Valencia.

Herrero, R., M.J. Asíns, E.A. Carbonell, and L. Navarro. 1996. Genetic diversity in the orange subfamily Aurantioideae. II. Genetic relationships among genera and species. Theor. Appl. Genet. 93:1327-1334.

Herrero, R., M.J. Asíns, E.A. Carbonell, and L. Navarro. 1996. Genetic diversity in the orange subfamily Aurantioideae. I. Intraspecies and intragenus genetic variability. Theor. Appl. Genet. 92:599-609.

Hodgson, R.W. 1967. Horticultural varieties of citrus, p. 431-591. In: The citrus industry. Vol. 1 (W. Reuther, H.J. Webber, and L.D. Batchelor (eds.). Div. of Agr. Sci., Univ. of California, Berkeley.
Huff, D.R. and J.M. Bara. 1993. Determining genetic origins of aberrant progeny from facultative apomictic Kentucky bluegrass using a combination of flow cytometry and silver-stained RAPD markers. Theor. Appl. Genet. 87:201-208.

Jones, C. J., K.J. Edwards, S. Castaglione, M.O. Winfield, F. Sala, C. van de Wiel, G. Bredemeijer, B. Vosman, M. Matthes, A. Daly, R. Brettschneider, P. Bettini, M. Buiatti, E. Maestri, A. Malcevschi, N. Marmiroli, R. Aert, G. Volckaert, J. Rueda, R. Linacero, A. Vazquez, and A. Karp. 1997. Reproducibility testing of RAPD, AFLP and SSR markers in plants by a network of European laboratories. Mol. Breeding 3:381-390.

Kalendar, R., T. Grob, M. Regina, A. Suoniemi, and A. Schulman. 1999. IRAP and REMAP: Two new retrotransposon-based DNA fingerprinting techniques. Theor. Appl. Genet. 98:704-711.

Malik, M.N., R.W. Scora and R.K. Soost. 1974 Studies on the origin of the lemon. Hilgardia 42:361-382.

Protopapadakis, E. and X. Papanikolau. 1999. Use of four isozymatic systems in lemon and lemon-like citrus cultivars to detect their genetic diversity. J. Hort. Sci. and Biotechnol. 74(1):26-29.

Ruiz, C. and M.J. Asíns. 2003. Comparison between Poncirus and Citrus genetic linkage maps. Theor. Appl. Genet. 106:826-836.

Ruiz C., M.P. Bretó, and M.J. Asíns. 2000. An efficient methodology to identify sexual seedlings in citrus breeding programs using SSR markers. Euphytica 112:89-94.

Russo, M.P., M. La Rosa, A. Astuto, and G. Reforgiato-Recupero, 1998. Randomly amplified polymorphic DNA (RAPD) analysis of selfed progeny for the understanding of the genetic origin of some lemon cultivars. Adv. Hort. Sci. 12:85-88.

Smith, J.S.C., E.C.L. Chin, H. Shu, O.S. Smith, S.J. Wall, M.L. Senior, and S.E. Mitchell. 1997. An evaluation of the utility of SSR loci as molecular markers in maize (Zea mays L.): Comparisons with data from RFLPs and pedigree. Theor. Appl. Genet. 95:163-173.

Sneath, P.H.A. and R.R. Soakal, 1973. Numerical taxonomy. W.H. Freeman, San Francisco.

Swingle, W.T. 1943. The botany of Citrus and its relatives of the orange subfamily. In: H.J. Webber and L.D. Batchelor (eds.). The citrus industry. Univ. of California, Berkeley.

Torres, A.M., R.K. Soost, and U. Diedenhofen. 1978 Leaf isozymes as genetic markers in Citrus. Amer. J. Bot. 65:869-881.

Vicient, C.M., M.J. Jääkeläinen, R. Kalendar, and A.H. Schulman. 2001. Active retrotransposons are a common feature of grass genomes. Plant Physiol. 125:1283-1292.

Wright, S. 1978. Evolution and the genetic of populations. Vol. 4: Variability in and among natural populations. Univ. of Chicago Press. 